\title{
TECHNICAL INNOVATIONS IN GLOBAL EARLY WARNING IN SUPPORT OF DESERT LOCUST AREA- WIDE MANAGEMENT
}

\author{
K. CRESSMAN \\ Plant Production and Protection Division, Food and Agriculture Organization of \\ the United Nations (FAO), Rome, Italy; keith.cressman@fao.org
}

\begin{abstract}
SUMMARY
Technical innovations can play an important role in the effective management of transboundary pests if they are well integrated with participation and collaboration by affected countries and coordinated by a centralised body. This is particularly relevant to those migratory pests that can easily and rapidly move across regions and continents to simultaneously threaten food security and livelihoods in numerous countries. Innovations to FAO's successful desert locust global monitoring and early warning system are highlighted and the lessons learned can be applied and adapted to other emerging transboundary threats such as the fall armyworm in Africa and the red palm weevil.
\end{abstract}

Key Words: Schistocerca gregaria, transboundary plant pests and diseases, remote sensing, surveillance, forecasting, early warning, geographic information systems, unmanned aerial vehicles

\section{INTRODUCTION}

Transboundary pests are migratory insects and disease vectors that easily move from one country to another and can rapidly traverse regions and travel great distances to threaten crop production throughout the world. While the desert locust Schistocerca gregaria Forskål is probably the most well-known and best studied of the migratory insect pests, there are other notable transboundary pests such as the migratory locust Locusta migratoria (L.), the Moroccan locust Dociostaurus maroccanus (Thunberg), and Italian locust Calliptamus italicus (L.), as well as the red palm weevil Rhynchophorus ferrugineus (Olivier) and the fall armyworm Spodoptera frugiperda (Smith) that are becoming an increasing threat to agriculture and livelihoods in Africa and Asia (Fig. 1). 
The desert locust is an ancient insect, dating from millions of years and coexisting with early man until the advent of cultivation, when it became what is considered today as the world's most dangerous migratory insect pest. The unique behaviour of the desert locust allows it to quickly take advantage of optimal environmental conditions by rapidly increasing in number and forming highly migratory swarms that can affect some 20 percent of the earth's land surface and livelihoods of millions of people in Africa, the Middle East and Asia.

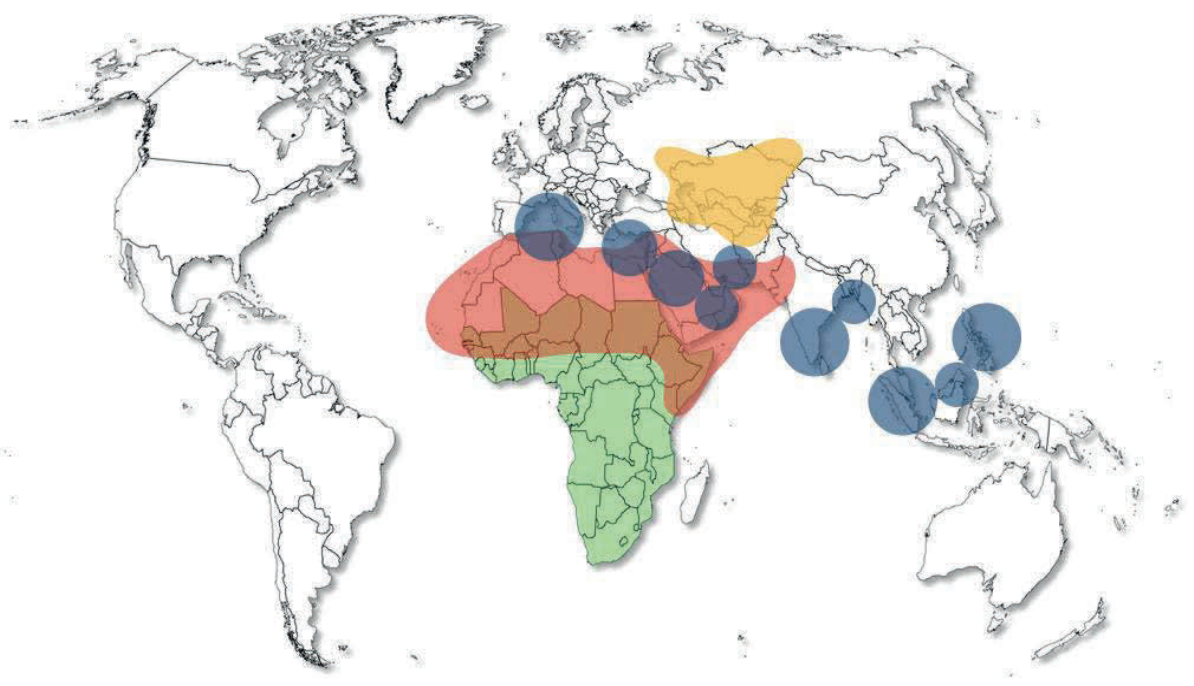

Figure 1. Major transboundary pests in Africa and Asia: Desert locust distribution area (red), fall armyworm (green), red palm weevil (blue), and migratory / Moroccan / Italian locusts in Central Asia (yellow) (source FAO DLIS).

It was not until the early twentieth century that efforts began in earnest to systematically monitor the pest across its vast desertic habitat stretching from West Africa to India, consisting of some of the world's driest and remotest areas. In 1943, the Desert Locust Information Service (DLIS) was established in the UK, which was the basis for the future global forecasting and early warning system. The DLIS was responsible for the systematic collection and mapping of desert locust infestations so that seasonal breeding areas could be identified, and a better understanding could be gained about the formation of swarms and their migratory patterns. In 1978, FAO assumed the centralised responsibility of the DLIS.

\subsection{Desert Locust Biology and Behaviour}

Low numbers of isolated desert locust are present somewhere within its vast habitat throughout the year. This area includes about 30 countries and covers some 16 million $\mathrm{km}^{2}$ of desert in North Africa, the Arabian Peninsula and south-western Asia (Fig. 2). 
The individualistic solitarious adults and hoppers (the nymphal stage) are wellcamouflaged to blend in with their environment as a means of protection from predators. The adults are passive fliers at night, drifting up to $400 \mathrm{~km}$ downwind. Often the winds bring the adults into areas of recent rainfall, which wets the sandy soil sufficiently for females to lay eggs that hatch after about two weeks. The resulting hoppers shed their skins (moulting) on about a weekly basis six times before becoming an adult. The entire lifecycle lasts about three months, but may last up to a half year, as adults may remain immature for months in low temperatures or in the absence of regular rains. Desert locust do not have a dormant stage, they do not overwinter, and eggs cannot survive from one year to the next.

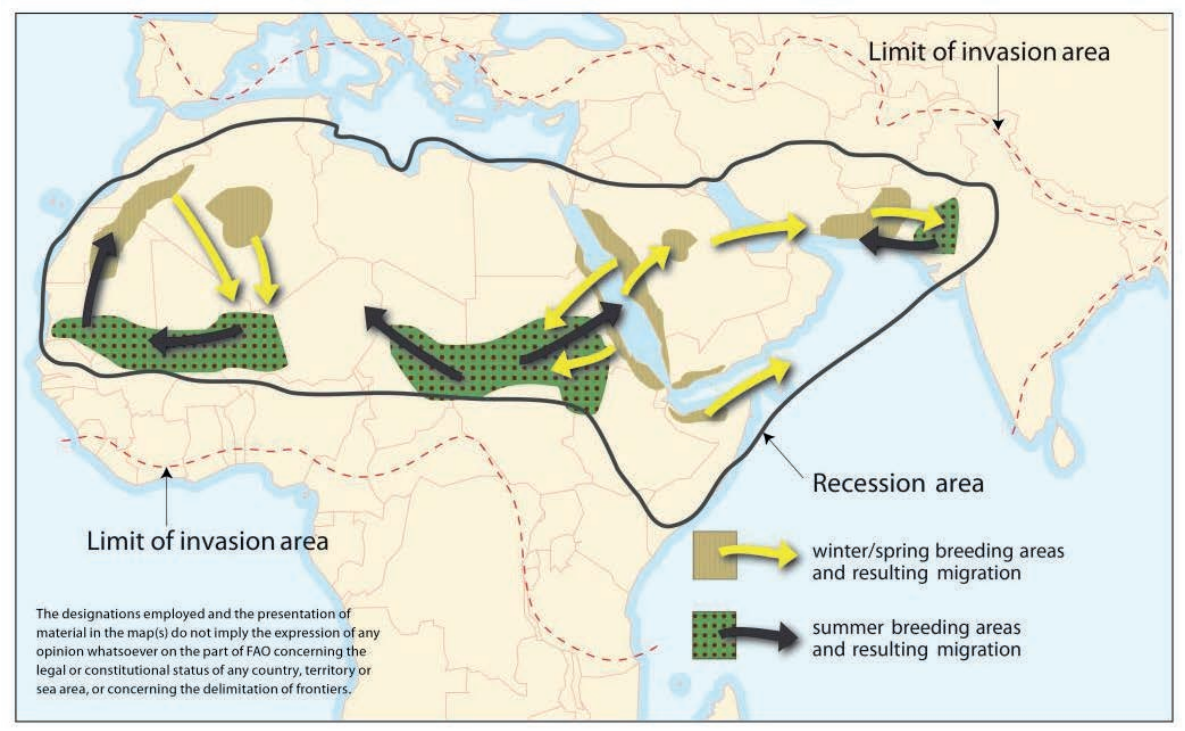

Figure 2. Desert locust recession and invasion areas, and their seasonal migration patterns (source FAO).

Locusts will quickly take advantage of exceptionally heavy and often short-lasting rainfall, whether localized or widespread, that cause ecological conditions to become favourable for breeding and survival. Once annual vegetation dries out, locusts tend to concentrate in those areas that still remain green, increase in density and form small groups that may fuse together and develop into hopper bands and adult swarms. This behavioural phase change is referred to as gregarisation. Swarms fly during the daylight hours, moving more than $200 \mathrm{~km}$ in a single day. This allows them to easily traverse Africa and to cross water bodies such as the Red Sea, the Mediterranean Sea and the Arabian Sea. They also can extend further north, south and east from their normal habitat and invade several dozen countries (Fig. 2). In October 1988, swarms migrated some 5,000 km across the Atlantic Ocean from West Africa to the Caribbean (Rosenberg and Burt 1999). 
A single desert locust is able to consume its own weight, approximately 2 grams of food every day. A $1 \mathrm{~km}^{2}$ sized swarm generally contains about 40 million adults (Pedgley 1981). The high number of locusts and their voracious appetite can pose a serious threat to agriculture and food security. To put this into perspective, a swarm the size of Bamako, Mali will eat the same amount of food in one day as half the entire population of Mali. Similarly, a swarm the size of Vienna will consume the same amount of food in one day as everyone in Austria and Switzerland, while a swarm the size of New York City will eat as much food in a single day as all the residents in the states of New York and Pennsylvania.

Desert locust plagues do not develop overnight. Instead, they evolve from a serious of events in which locust numbers steadily increase. It starts with a calm period of recession, when locusts are normally present at low densities in semi-arid or arid areas, causing no significant crop damage, and hopper bands and swarms are absent. This is followed by localized outbreaks that may cover only a few hundred square kilometres within a single country. If an outbreak is not detected or controlled and if good rains continue to fall, then the outbreak could increase in size and expand into several neighbouring countries, leading to an upsurge. Similarly, if an upsurge is not controlled and rains continue, then a plague could develop on a regional, continental, or global level. Normally, gregarisation occurs after at least two successful generations of breeding. Several more successive generations must take place before the majority of the populations consist only of hopper bands and adult swarms. Therefore, it takes at least one year for a plague to develop. On the contrary, a plague can collapse very rapidly in a matter of months due to effective control, unusually low temperatures and a lack of rainfall.

Desert locust recession and plague periods occur irregularly in response to the sporadic nature of rainfall in the desert. Since 1860, there have been nine plagues and major upsurges that were interrupted by periods of recessions and localised outbreaks (Symmons and Cressman 2001). These lasted from several months to several years or more (Fig. 3).

The last major upsurge or regional plague occurred in 2003-2005. In addition to an unusually cold winter, it took nearly USD 600 million and 13 million litres of insecticide sprayed by ground and aerial campaigns to bring the plague under control (Brader et al. 2006). In West Africa, more than 8 million people were affected, up to $100 \%$ of cereal crops were lost in some areas, and some $60 \%$ of household heads became indebted in Mauritania, while $90 \%$ of households in Burkina Faso received food aid.

\subsection{Climate Change Impact}

Changes in the climate will affect desert locust habitats, breeding, migration, and plague dynamics. It is well known that the current climate change is causing temperatures to increase. Warmer temperatures will extend the length of the summer, winter and spring breeding periods and allow desert locust eggs and hoppers to develop faster as long as this is associated with a continuation or increase of good rains. This is likely to be most pronounced during the winter and may allow an extra generation of breeding to take place (Cressman 2013). 
Warmer temperatures could also potentially affect desert locust migration by allowing solitarious adults to fly longer during nights, especially during the colder portions of the year. Consequently, adults may arrive at a destination sooner or reach new areas further away. Warm temperatures could allow swarms to take off earlier in the morning, resulting in a longer period of flight during the day and a greater displacement distance. In other words, swarms could reach new places that have not been reachable up to now. Climate change could also allow swarms to fly higher than $1800 \mathrm{~m}$, which is the general limit of flight due to temperature. If this is the case, then the Atlas Mountains in north-western Africa, the Hoggar Mountains of Algeria, the Jebel Akhdar Mountains in northern Oman, the mountains in the interior of Iran, and the mountain ranges along both sides of the Red Sea may no longer be natural barriers that impede migration. On the other hand, if warmer temperature regimes were to become extremely hot, for example above $50^{\circ} \mathrm{C}$, then desert locust presence and survival could become limited in some areas of the Sahara and the Arabian Peninsula (Meynard et al. 2017).

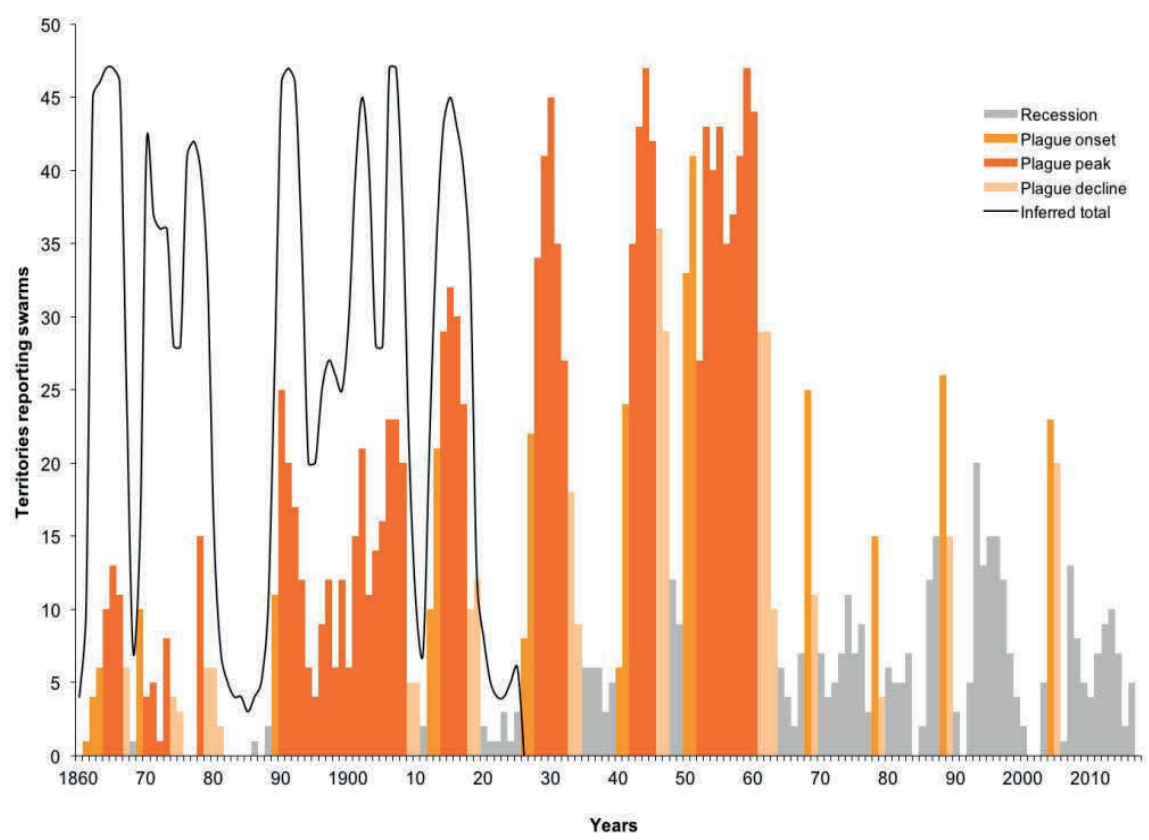

Figure 3. Desert locust plagues and recessions between 1860 and 2017 (source FAO DLIS).

The impact of climate change on the spatial variability of rainfall in desert locust breeding areas remains unclear. There is some evidence that rainfall could increase during the summer in seasonal breeding areas of the northern Sahel in West Africa and in the Yemen interior that could cause locust numbers to increase faster than normal. There appears to be more widespread agreement concerning an increase in extreme rainfall events. 
It is worthy to note that unusually heavy rains have been responsible for locust plagues in the past, such as a cyclone in 1968 in Oman that caused a plague the following year and widespread heavy rains from Senegal to Morocco in October 2003 that led to a regional plague for the next two years.

The effects of wind are less certain, but any changes in wind speed, direction and circulation flows are likely to affect desert locust migration and could allow adults and swarms to reach new areas. Warmer temperatures in combination with shifting wind patterns and decreased rainfall could permit new migration routes into Southern Europe and Central Asia. In general, however, further research is required to better understand the impacts of climate change and variability on the desert locust population dynamics and migration.

\section{MONITORING AND EARLY WARNING}

Locust-affected countries and FAO have adopted a preventive control strategy for the area-wide management of desert locust in order to reduce the frequency, duration and intensity of plagues (Fig. 4). Successful preventive control requires effective early detection and warning, rapid response, good communications and contingency planning. The former consists of monitoring weather, ecological conditions and desert locust populations on a regular basis throughout the vast recession area that stretches from the Atlantic coast in West Africa to western India. This is accomplished through observations made by ground teams during survey and control operations that are recorded and sent to the national locust control centres and, from there, to FAO's centralised global system operated by the DLIS in Rome (Fig. 5).

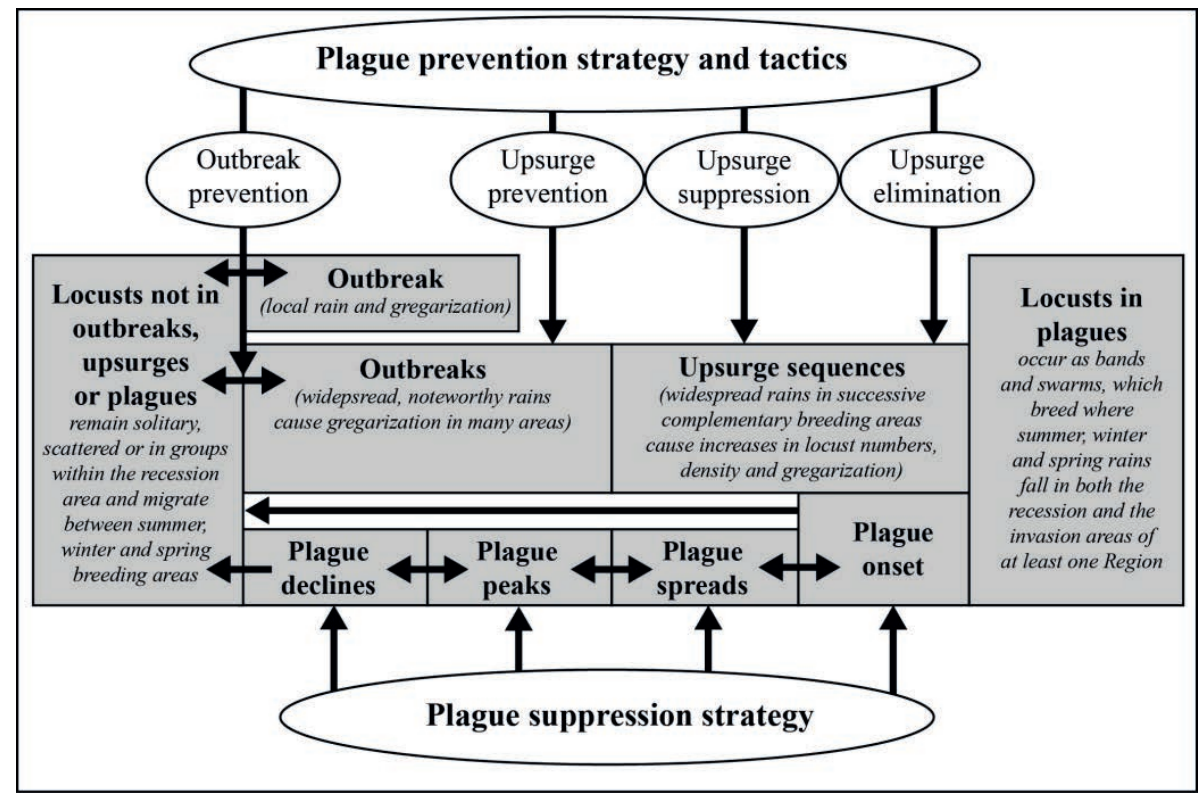

Figure 4. Desert locust preventive control strategy (source Magor et al. 2007). 


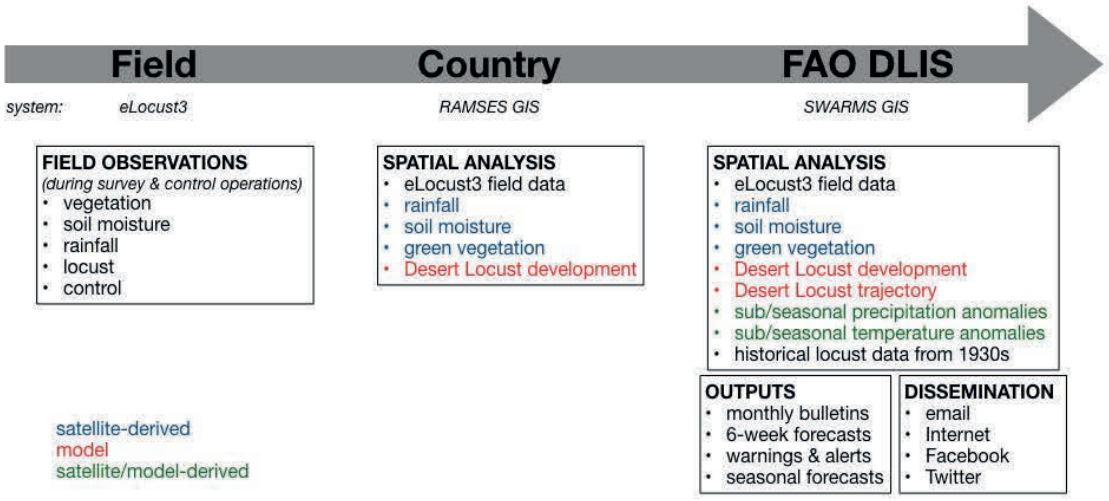

Figure 5. Information flow in the FAO global desert locust early warning system (source FAO DLIS).

Each locust-affected country is responsible for monitoring and controlling desert locust in its own territory. In most countries, a dedicated national locust centre within the Ministry of Agriculture and Plant Protection Department assumes these responsibilities. Specialized teams undertake ground surveys using four-wheeleddrive vehicles in the desert, looking for annual vegetation that may be green and harbouring desert locust hoppers or adults.

If important infestations are detected, then control operations are immediately implemented to prevent the locust population from increasing further and spreading. The obvious challenge is to find and treat these relatively small localities within a vast and remote area that is devoid of infrastructure and inhabitants. This is further complicated by increased conflict and insecurity in many places, preventing national locust teams from undertaking the necessary survey and control operations. The DLIS plays an important role to guarantee a coordinated action amongst countries during periods of simultaneous outbreaks and the presence of swarms in more than one country.

In the past, early warning was hampered by difficulties in accessing remote desert locust habitats and sending timely information. Although tremendous efforts were made to systematically map desert locust infestations and analyse changes in population dynamics, this was often hampered by information that usually took weeks or months to arrive from the field. As a result, it was impossible to provide advice for decisions to be made to allow responding on time.

An effective early warning system for any transboundary pest relies on the transmission of geo-referenced data in real- or near real-time from the field to a centralised collection point where data can be analysed rapidly in order to provide timely and meaningful advice for decision makers. Timeliness becomes even more essential when dealing with a transboundary pest such as the desert locust that has the ability to rapidly increase in number and form swarms that can quickly move from one area to another. 


\section{INNOVATIONS}

The present state of the global FAO desert locust monitoring and early warning system is a direct function of continuous innovation. It has evolved alongside advances in communication, computer and spatial technologies during the past several decades.

\subsection{Advances in Communications, Geographic Information Systems and Transport}

At the beginning of the last major desert locust plague in 1987, telex was the primary communications means for countries to transmit data and reports from the field to the DLIS in Rome. Similarly, FAO used telex to send advice, warnings and monthly bulletins and forecasts. By the end of the plague in 1989, telex had been replaced by facsimile. Although this was an improvement because additional information formats such as tables and photos could be transmitted, it remained somewhat limited since not everyone had a fax machine. These limitations were overcome with the introduction of email in the mid-1990s and its widespread use from 2000 onwards. This was further expanded as a greater number of individuals began using personal computers and mobile phones.

Until the mid-1990s, field data were plotted and analysed manually using paper maps, transparencies and coloured pencils. This tedious and labour-intensive system was replaced by custom-made geographic information systems (GIS) to allow rapid mapping and detailed spatial data analysis. The Schistocerca Warning and Management System (SWARMS) in the DLIS was one of the first uses of GIS for operational monitoring rather than production of one-time static maps (Healey et al. 1996). In 2000, FAO developed a standard custom GIS, Reconnaissance and Management System of the Environment of Schistocerca (RAMSES), for locustaffected countries to manage and analyse their own survey and control results with remote sensing imagery and historical data. In 2014, RAMSES was redesigned as open-source software with a spatial database.

The remote locust habitats in the desert have become progressively easier to access in most countries due to improvements in transport and infrastructure. Four-wheeleddrive vehicles have replaced camels that were used by locust survey and control teams in the past. A proliferation of tracks and roads in the desert associated with increased development allow access to a greater number of places in a shorter amount of time. In this way, survey teams can monitor a larger area with the same amount of resources.

Even though countries could send and receive information faster and ground teams could reach desert locust habitats easier, the field teams were unable to transmit high quality data in real-time from the location of the survey or the control operations, often in the middle of nowhere, to national locust centres and the DLIS. FAO addressed this issue by developing a custom tool, eLocust, that is a rugged handheld tablet for recording field observations and sending them by satellite in real-time to the national locust centre. This was introduced in 2006 and it revolutionized desert locust early warning overnight. Suddenly, weather, ecological, locust and control data were available within a few minutes from anywhere in the desert between West Africa and India. National locust directors now could know at any given time the exact location of every field team and results of the survey and control operations. 
An upgraded version in 2015 of the custom tool, eLocust3, allowed users in the field to enter more survey and control data, navigate to potential areas of green vegetation without the need for internet connectivity, and take photos and videos of the situation.

\subsection{Satellite-based Remote Sensing}

Despite such advances in communications and transport, the desert continues to be huge and vast. It remains unattainable for any single locust-affected country to have sufficient resources to scour each and every hectare in search of desert locust. Therefore, all efforts must be made to somehow delimit the large areas that need to be searched and prioritise them to those that have the greatest potential of containing important locust populations. Satellite-based remotely sensed imagery is routinely used to help guide field teams to such places. This is undertaken in a systematic manner by first determining those regions or areas where rains may have fallen by using satellite-based rainfall estimates. While model-derived estimates may be more accurate in terms of rainfall quantity, satellite-based estimates are a better spatial indicator of rainfall (Dinku et al. 2010).

Once a region of possible rainfall has been identified, then multi-temporal and multi-spectral image analysis that exploits the mid-infrared, near-infrared and red wavelengths is applied to daily observations from NASA's $250 \mathrm{~m}$ resolution Moderate-Resolution Imaging Spectroradiometer (MODIS, Aqua and Terra) to determine if there was a response of annual vegetation to the rainfall (Pekel et al. 2011). This is the vegetation required by desert locust for food and shelter. An automatic processing chain combines the daily imagery into a ten-day dynamic vegetation greenness map that shows the three-month greenness history of each 250 $\mathrm{m}$ pixel in order to monitor the development of green vegetation in those areas that received rainfall or runoff (Fig. 6). These maps are used by locust-affected countries to position and prioritize surveys and by FAO DLIS for analysis and forecasting. They can also be used by teams that are equipped with eLocust 3 to help navigate to green areas in the field.

The internet has become the de facto means of delivering imagery and other data to analysts and decision-makers. The DLIS is constantly seeking new ways to improve the timely distribution of remote sensing products. While some delays may be due to satellite reception, there are other delays that are attributed to processing the data into map products. The latter is being actively addressed by utilizing Google Earth Engine technology whereby the user can process the image online in less than a few minutes by taking advantage of parallel and cloud computer technologies. This on-demand system is not only faster but may be more sustainable in the future compared to traditional processing and delivery chains. 


\subsection{Unmanned Aerial Vehicles for Surveillance and Focused Control}

In the past few years, unmanned aerial vehicles (UAVs or drones) have become increasingly available for public use, and the technology is rapidly improving and expanding to new fields of use. The use of fixed- and rotary-wing drones could potentially improve desert locust monitoring, early warning and rapid response control, while reducing the costs of survey and control operations. Drones could supplement current tools utilized for monitoring in order to help guide ground teams to green vegetation and locust infestations. For example, the latest satellite imagery would be analysed to identify regions or areas within a country where ecological conditions may be favourable for locusts, specifically, where recent rains have occurred and where green vegetation may be present.

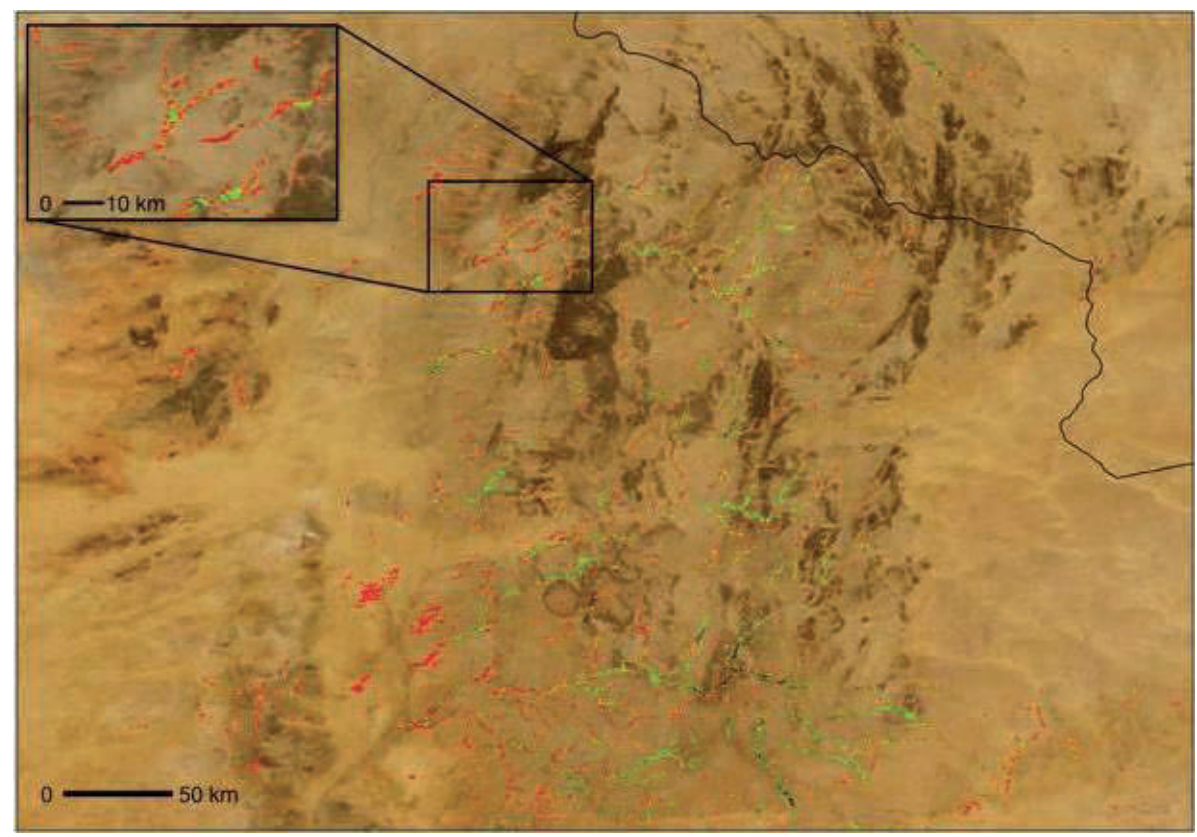

Figure 6. A 10-day dynamic NDVI map for 1-10 September 2017 indicating where annual vegetation in northern Mali has become green within the last 10 days (red), 20 days (orange) and 30 days (yellow) along dry river beds (wadis) in between the Adrar des Iforas hills.

Green and darker colours indicate vegetation that has been green for several months, probably perennial vegetation such as trees, oases and forests. Each pixel is $250 \times 250 \mathrm{~m}$ $\left(0.0625 \mathrm{~km}^{2}\right)$ (source FAO DLIS).

This initial filtering will help to reduce the large and vast areas that need to be checked by ground teams. A team would then be deployed to this area to undertake surveys. The team would be equipped with a small, portable long-range fixed-wing drone. This drone should cover a radius of about 50-100 km. The team would programme the route itinerary of the drone and launch it. The drone would capture and process information along the route using optical and/or hyperspectral sensors to 
detect areas of green vegetation and moist soil, as well as the presence of any sizeable hopper or adult concentrations (groups, bands, and swarms). Once the drone returns to the survey team, the processed data would then be transferred to eLocust 3 and the team would use the results to go directly to the areas of interest or change direction if the results of the flight do not indicate the presence of favourable conditions for desert locust.

A ground team could also carry a small portable rotary drone with them during surveys to a specific location identified from above or an area that may contain vegetation or locusts. The drone would help the team get a better idea of the ecological conditions and the locust situation by taking low-level images of the area to identify the presence of green vegetation and locusts. If the team stops in an area with green vegetation or crops, the drone could look in situ for locusts and also determine the size of the potentially infested area. If the location is less precise, then the team could launch the rotary drone to look for any signs of green vegetation or favourable breeding areas within a $5 \mathrm{~km}$ radius. The drone could also be used to collect information from areas that are not accessible to the ground team due to topography or insecurity.

Lastly, a rotary drone could be used to undertake targeted control treatments of small infested areas and in areas that are difficult to access by ground teams (Benavente-Sánchez et al., this volume). This is highly desirable and advantageous because it makes control operations much safer and more precise. Field officers would avoid coming into contact with the chemicals as drones would be doing the spraying. Spot control would involve spraying only the specific locust infestation rather than treating the entire area, thus reducing pesticide usage and protecting the environment.

\subsection{Forecasting the Time and Scale of Breeding and Early Warning Systems}

The innovative tools mentioned up to this point are primarily utilized for directing national locust field teams in managing the current situation. Another set of technologies are exploited for locust prediction that involve the adaptation of cuttingedge methodologies to operational monitoring and forecasting.

Remote sensing imagery has traditionally been used for monitoring rainfall and vegetation. More recently, a new product has been developed to monitor ground soil moisture down to $10-15 \mathrm{~cm}$ below the surface. This moisture is critical for breeding to allow egg-laying and hatching, as well as the growth of annual vegetation necessary for locust feeding and shelter. Similar to other satellite-derived products, soil moisture maps are updated every ten days. This facilitates comparative analysis with rainfall vegetation imagery. The product will be another field tool to help delimit the large areas to be surveyed by guiding teams to specific places where breeding may be underway.

The DLIS utilizes seasonal predictions of monthly precipitation and temperature anomalies that are issued six months in advance and updated every month. These maps can help to forecast the timing and scale of locust breeding several months ahead, giving extra time for national locust programmes for planning and prepositioning resources. Sub-seasonal predictions for up to four weeks in advance and updated twice a week can be used for short-term advice and warnings to assist in 
managing operations, especially during control campaigns. Both products are derived from several sophisticated weather models and may vary considerably from month to month. Hence, they can be less reliable at times and must be interpreted with caution.

At present, two models are used in desert locust early warning, an egg and hopper development model and a trajectory model. The former estimates the time required for egg and hopper development based on location. This is useful for forecasting the timing of breeding and planning field operations. The trajectory model is used to estimate the displacement of locust adults and swarms forward and backward in time. The model relies on meteorological data such as wind speed and direction, pressure and temperature provided by the European Centre for Medium-Range Weather Forecasts (ECMWF) every 12 hours for the desert locust recession area (Fig. 2.). This allows the forecaster to select the height or temperature level of flight and, by indicating the take-off or landing date and time, estimate where the adults or swarm came from or will go to.

\section{SUCCESSES AND LESSONS LEARNED}

The global desert locust early warning system operated by FAO is one example of successful area-wide pest management. Outbreaks, the precursors to upsurges and plagues, are now easier to detect and respond to on time due to improvements in monitoring and early warning (Fig. 4). This has resulted in a significant decrease in the duration, intensity and frequency of desert locust plagues. As mentioned previously, there were nine major plagues and ten major upsurges from 1860 to 2000, some of which lasted up to 14 years and affected 50 or more countries. Since 2000, there has been only one major upsurge and no plagues (Fig. 3).

This success can be attributed to a number of important factors. As the desert locust is such a well-known and old pest with a long history, countries are exceptionally aware of its importance and potential threat. This high visibility facilitates national interest at all levels and helps to engage the relevant stakeholders. Locust-affected countries understand the transboundary nature of the desert locust and, hence, willingly engage in joint monitoring and area-wide control activities as well as development projects to strengthen national capacities. Regardless of political relations, strong networks exist amongst countries that contribute to the regular and timely sharing of high-quality data and exchange of reliable information. Without this, an early warning system would not be possible.

The latest technologies are utilized and adapted in an innovative manner for the development of useful and well-focused tools that can be used by those involved in locust survey, control, reporting and forecasting. A bottom-up approach is used for these developments based on user requirements and feedback. The products, methodologies and tools are constantly updated to reflect changes in latest technologies and user needs. Substantial training and retraining are provided to each country using the train-the-trainers strategy, in which national master trainers are trained in the technology as well as in teaching and communications, so that they can provide essential training at all levels to national locust staff. Clear, concise, and imaginative training material and programmes are designed and updated to complement this process, supplemented by online videos for self-learning. 
It is important to develop products and tools that are sustainable, can be maintained locally and used for as long as possible. Whenever possible, existing infrastructure, resources and expertise should be utilized and, if necessary, expanded rather than reinventing something that already exists. When developing an area-wide pest management programme, for example, that has a requirement for data collection in the field, it is far better to take advantage of the mobile phones that most farmers and extension agents already have, as well as the know-how to use them. This eliminates the need to develop, procure, distribute, and maintain a different device and to provide relevant training. Instead, it would only be necessary to develop an app for data collection and recording that works on the mobile phones. If data transmission is required, and there exists sufficient mobile telephone network coverage, then there is no need to rely on satellite communication, which is not only more expense but also requires additional hardware, maintenance, and training.

It is crucial to use technologies that are appropriate and relevant. For example, the Sterile Insect Technique (Dyck et al. 2021), requested by some countries, is not an appropriate control strategy for desert locust because of the size of its vast recession area and the fact that the released locusts would cause damage consuming crops. On the other hand, it has been extremely successful in contributing to the eradicating other pests such as the pink bollworm Pectinophora gossypiella (Saunders) in the southwestern USA and northern Mexico (Staten and Walters, this volume), because it is not migratory, the released moths do not affect the cotton crop, and it was largely restricted to this host plant within this large geographic area.

Lastly, it is important to remain relevant by never ceasing to innovate in order to take advantage of the potential benefits and applications offered by the latest technologies. One example is the integration of drones and high-resolution satellite imagery into area-wide pest management programmes for monitoring and control. While this should not be a substitute for ground means, it can certainly supplement current efforts to monitor more effectively large areas and undertake safer and more precise control operations.

The innovative use of new technologies and tools in managing transboundary pests is unlikely to be entirely successful if it is not coupled with strong collaboration amongst beneficiary countries that is overseen by a centralised coordinating body. For example, 30 frontline countries affected by the desert locust share field data amongst themselves and with the DLIS. This allows DLIS to continual monitor the situation, forecast its developments, and provide timely and accurate early warning. A centralised coordinating structure also allows the implementation of standardized methodologies and training material in all countries as well as coordinated action between countries during outbreaks, upsurges, and plagues.

All of the lessons learned from the desert locust experience can be applied and adapted to other transboundary pests such as other locusts, as well as the red palm weevil and the fall armyworm, as a means to better manage these pests, protect crops, and enhance food security. 


\section{REFERENCES}

Brader, L., H. Djibo, F. G. Faye, S. Ghaout, M. Lazar, P. N. Luzietoso, and M. A. Ould Babah. 2006. Towards a more effective response to desert locusts and their impacts on food security, livelihoods and poverty: Multilateral evaluation of the 2003-05 desert locust campaign. FAO, Rome, Italy.

Cressman, K. 2013. Climate change and locusts in the WANA region, pp. 131-143. In M. V. K Sivakumar, R. Lal, R. Selvaraju, and I. Hamdan (eds.), Climate change and food security in West Asia and North Africa. Springer, The Netherlands.

Dinku, T., P. Ceccato, K. Cressman, and S. J. Connor. 2010. Evaluating detection skills of satellite rainfall estimates over desert locust recession regions. Journal of Applied Meteorology and Climatology 49: 1322-1332.

Dyck, V. A., J. Hendrichs, and A. S. Robinson (eds.). 2021. Sterile Insect Technique - Principles and practice in Area-Wide Integrated Pest Management. Second Edition. CRC Press, Boca Raton, Florida, USA. 1200 pp.

Healey, R. G., S. G. Roberston, J. I. Magor, J. Pender, and K. Cressman. 1996. A GIS for desert locust forecasting and monitoring. International Journal of Geographical Information Systems 10: 117-136.

Magor, J. I., P. Ceccato, H. M. Dobson, J. Pender, and L. Ritchie. 2007. Preparedness to prevent desert locust plagues in the Central Region, an historical review. Desert Locust Technical Series, AGP/DL/TS/35. FAO, Rome, Italy. 184 pp.

Meynard, C. N., P. E. Gay, M. Lecoq, A. Foucart, C. Piou, and M. P. Chapuis. 2017. Climate-driven geographic distribution of the desert locust during recession periods: Subspecies' niche differentiation and relative risks under scenarios of climate change. Global Change Biology 23: 4739-4749.

Pedgley, D. 1981. Desert locust forecasting manual. Centre for Overseas Pest Research, Chatham, UK.

Pekel, J. F., P. Ceccato, C. Vancutsem, K. Cressman, E. Vanbogaert, and P. Defourny. 2011. Development and application of multi-temporal colorimetric transformation to monitor vegetation in the desert locust habitat. IEEE Journal of Selected Topics in Applied Earth Observations and Remote Sensing 4: 318-326.

Rosenberg, L. J., and P. J. A. Burt. 1999. Windborne displacements of desert locusts from Africa to the Caribbean and South America. Aerobiologia 15: 167-175.

Symmons, P., and K. Cressman. 2001. Desert locust guidelines. 1. Biology and behaviour. 2nd edition. FAO, Rome, Italy. 43 pp. 